\title{
APLIKASI GAME BATTLE PUZZLE DENGAN METODE BEST FIRST SEARCH
}

\author{
Aqil Muhammad Arviansyah ${ }^{1}$, Christnatalis $^{2}$ \\ Address: Universitas Prima Indonesia, Program Studi Teknik Informatika, Indonesia ${ }^{1}$, Universitas Prima Indonesia, Program
} Studi Teknik Informatika, Indonesia ${ }^{2}$

Email: aqilarviansyah@gmail.com¹, christ.natalis@gmail.com²

\begin{abstract}
Abstrak
Perancangan aplikasi ini akan membuat suatu game berbentuk battle puzzle. Penelitian ini bertujuan untuk merancang konten sebuah game yang mendidik dan tetap bisa diterima oleh masyarakat, dimana penelitian ini menggunakan metode Best First Search serta menggunakan software microsoft visual basic.net 2008 dalam perancangannya. Metode Best First Search akan mencari ruang keadaan yang paling tepat untuk mencapai solusi permasalahan yang dapat diterima dan mempercepat proses kerjanya. Penelitian ini akan sangat bermanfaat bagi masyarakat khususnya anak-anak agar pengguna dapat meningkatkan pengetahuan dan wawasan serta menjadi bahan evaluasi intelligence pengguna.
\end{abstract}

\section{Keywords Game, Best First Search, and Microsoft Visual Basic. Net 2008}

\section{Latar Belakang}

Sekarang ini perkembangan teknologi semakin pesat sehingga mendorong berkembangnya Aplikasi maupun Video Game. Video Game atau Game bukanlah hal asing bagi masyarakat karena game adalah permainan yang menggunakan interaksi dengan antar muka pengguna melalui gambar yang dihasilkan. Video Game dapat bermanfaat jika dimainkan dengan benar, namun dapat membuat dampak buruk jika dimainkan secara berlebihan. Game tidak hanya bersifat hiburan, karena banyak game yang memiliki nilai edukasi didalamnya, namun banyak pengguna yang lebih memilih game yang hanya menawarkan hiburan semata dengan alasan bahwa dengan bermain game edukasi sangat membosankan. Game mudah didapatkan di platform Android, PC, Iphone, Windows Phone, dan sistem operasi lainnya dimana beberapa game dapat diunduh dan dimainkan secara gratis.

Dalam hal ini penulis ingin merancang sebuah game yaitu game battle puzzle. Game ini dimainkan dengan cara menyusun potongan gambar yang diacak untuk menjadi satu gambar yang utuh. Game Puzzle ini berbeda dengan game Puzzle pada umumnya, dimana user akan menyusun potongan gambar yang diacak sambil melawan atau bertanding dengan komputer. Game Battle Puzzle ini tidak semata-mata untuk hiburan karena memiliki nilai edukasi didalamnya, dimana pengguna harus berpikir dengan cepat. Secara konsep game ini menggunakan metode Best First Search dan menggunakan software Microsoft Visual Basic.net 2008.

Metode Best First Search merupakan kombinasi dari metode depth first search dan breadth first search dimana pencarian diperbolehkan mengunjungi node pada level lebih rendah jika node pada level lebih tinggi memiliki nilai yang lebih buruk. Metode ini akan sangat membantu dalam perancangan Game Puzzle karena akan memudahkan dalam mencari solusi yang tepat, sehingga penulis ingin melakukan penulisan skripsi yang berjudul "Aplikasi Game Battle Puzzle dengan Metode Best First Search".

\section{Metode}

Artificial Intelligence (Al) atau kecerdasan Buatan dapat didefinisikan sebagai cabang ilmu komputer yang mempelajari otomatisasi tingkah laku cerdas (intelligence) atau dengan kata lain Artificial Intelligence (Al) merupakan sub bidang pengetahuan komputer yang khusus ditujukan untuk membuat software dan hardware yang sepenuhnya bisa menirukan beberapa fungsi otak manusia. Dengan demikian diharapkan komputer bisa membantu manusia di dalam memecahkan berbagai masalah yang lebih rumit [1].

Dalam penelitian ini penulis menggunakan metode Best First Search. Best-First Search (BFS) merupakan 
metode yang membangkitkan simpul berikutnya dari sebuah simpul terbaik diantara semua leaf nodes (simpulsimpul pada level terdalam) yang pernah dibangkitkan. Best-First Search (BFS) merupakan kombinasi dari kelebihan metode Depth-First dan Breath-First Search. Pada setiap langkah proses BFS, dipilih simpul-simpul dengan menerapkan fungsi heuristik yang memadai pada setiap simpul yang dipilih dengan menggunakan aturanaturan tertentu untuk menghasilkan penggantinya [2].

$f^{\prime}(n)=g(n)+h(n)$

Dimana :

$\mathrm{f}^{\prime}=$ Fungsi evaluasi

$\mathrm{g}(\mathrm{n})=$ cost dari initial state ke current state (jumlah langkah)

$h(n)=$ perkiraan cost dari current state ke goal state

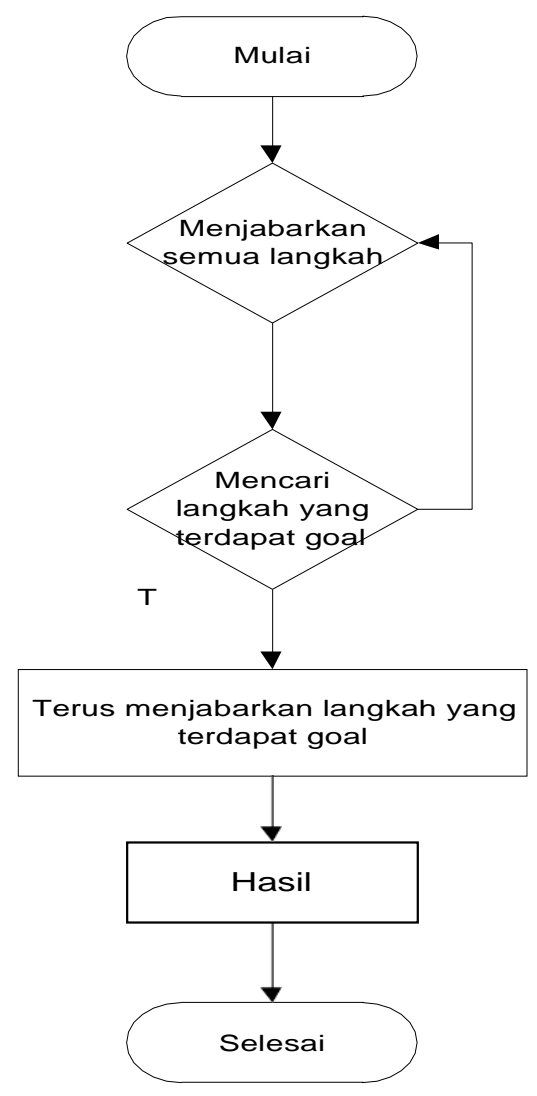

Gambar 1. Flowchart metode best first search

Metode best first search akan menjabarkan semua langkah dan mencari goal pada setiap langkahnya. Jika tidak terdapat goal maka akan dicari langkah selanjutnya, jika pada suatu langkah terdapat goal yang sama langkah tersebut akan dijabarkan sampai pada sutu langkah memiliki goal paling banyak. Metode ini akan selesai jika terdapat goal state pada setiap node nya.

Langkah-langkah yang akan dilakukan dalam penyelesain masalah yang akan dibahas pada penelitian ini adalah :

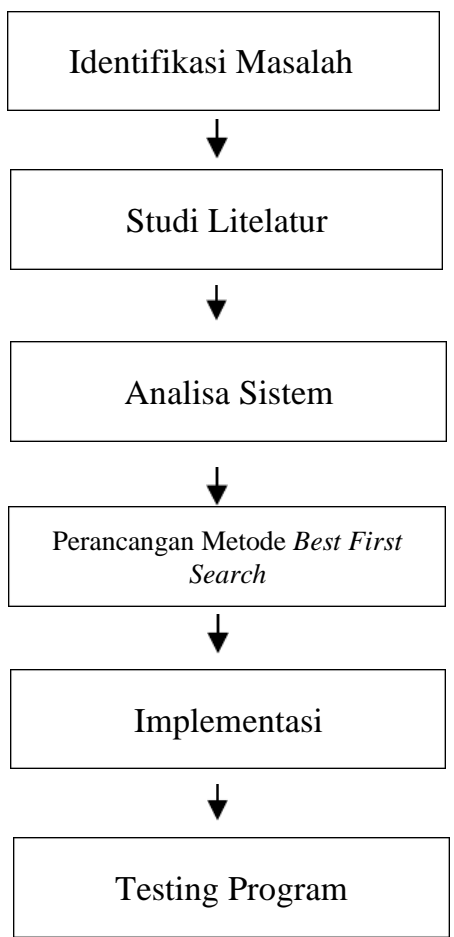

Gambar 2. Tahapan metode penelitian

1. Identifikasi Masalah

Pada tahapan ini akan dilakukan identifikasi masalah yang akan menjadi topik utama tugas akhir ini. Pada penelitian ini masalah yang di identifikasi adalah bagaimana cara kerja permainan game puzzle dan langkah-langkah dalam menyelesaikan game puzzle.

2. Studi Literatur

Berdasarkan pemahaman dari masalah, maka ditentukan tujuan yang akan dicapai dari penulisan ini. Pada tujuan ini ditentukan target yang dicapai, terutama yang dapat mengatasi masalah-masalah yang ada. Setelah masalah dianalisa, maka dipelajari literatur yang berhubungan dengan permasalahan. Kemudian literatur-literatur yang dipelajari tersebut diseleksi untuk dapat ditentukan literatur mana yang akan digunakan dalam penelitian ini. Sumber literatur didapatkan dari jurnal, artikel, yang membahas tentang game puzzle dan metode best first search.

3. Analisa Data 
Pada tahapan ini dilakukan analisis terhadap rumusan masalah dan batasan yang ada dalam skripsi ini. Analisis ini juga dilakukan untuk melakukan analisis spesifikasi sistem yang akan dibuat sesuai dengan batasan yang ada. Analisa sistem adalah aktivitas penguraian sistem ke dalam beberapa komponen yang membentuk sistem untuk mengkaji bagaimana komponen tersebut berinteraksi dan berfungsi. Untuk itu diperlukan tahapan analisis permasalahan terhadap suatu sistem untuk mengetahui alasan mengapa sistem tersebut diperlukan dan merumuskan dari sistem tersebut untuk merencanakan penjadwalan pembentukan sistem dan meminimalisir kesalahan yang mungkin terjadi didalam sistem tersebut, sehingga fungsi yang terdapat didalam sistem tersebut dapat bekerja secara optimal. Adapun tujuan dari diadakannya analisa masalah ini adalah untuk memahami dengan benar kebutuhan dari sistem baru dan mengembangkan sebuah sistem yang mewadahi kebutuhan dari sistem tersebut, serta untuk mengetahui seberapa baik bagian - bagian komponen tersebut bekerja dan berinteraksi. Analisa persyaratan terhadap sistem yang akan dirancang mencakup analisa fungsional yang mendeskripsikan fungsionalitas yang harus dipenuhi oleh perangkat lunak dan analisa nonfungsional yang mendeskripsikan persyaratan non-fungsional yang berhubungan dengan kualitas sistem.

4. Perancangan Metode Best First Search

Pada tahapan ini akan dilakukan perancangan model dari metode yang digunakan best first search. Perancangan model termasuk dalam persiapan tahapan-tahapan pengolahan data flowchart, persiapan tahapan-tahapan pengolahan data diagram alir. Tahap perancangan ini dilakukan sesuai hasil analisis. Beberapa tahap perancangannya yaitu perancangan arsitektur sistem, perancangan antarmuka, perancangan modul lainnya yang akan berintegrasi dalam suatu sistem.

5. Implementasi

Implementasi meliputi penggunaan aplikasi untuk menguji metode best first search dalam mencari jalan terceoat pada game puzzle dan memperoleh informasi berupa tingkat akurasi metode saat digunakan.

6. Testing Program

Pada tahap ini dilakukan beberapa tes terhadap sistem yang telah diimplementasikan. Testing dilakukan dengan memasukkan data pengujian tertentu, untuk melihat kesiapan sistem di dunia nyata.

\section{Hasil}

Hasil dari pengujian metode best first search dalam menyelasikan potongan gambar adalah:

Awal
\begin{tabular}{|l|l|l|}
\hline 3 & 7 & 4 \\
\hline 1 & & 6 \\
\hline 5 & 2 & 8 \\
\hline
\end{tabular}

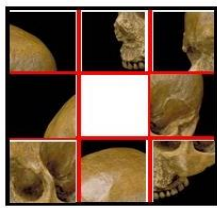

Gambar 3. Gambar yang diacak

Gambar diatas adalah awal saat potongan gambar diacak secara tidak beraturan (random).

\begin{tabular}{|l|l|l|}
\hline 3 & & 4 \\
\hline 1 & 7 & 6 \\
\hline 5 & 2 & 8 \\
\hline
\end{tabular}
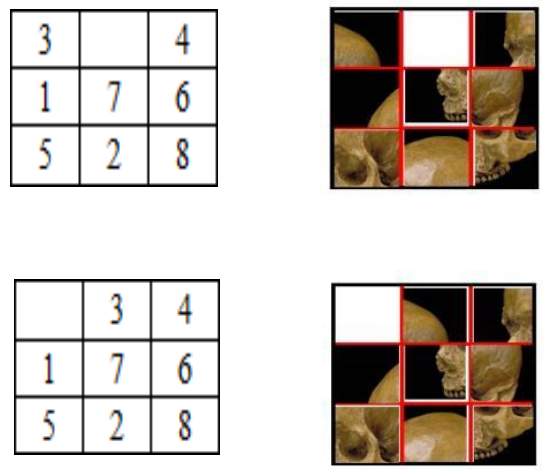

Gambar 4. Proses penyusunan potongan gambar

Gambar diatas adalah langkah selanjutnya dari metode best first search, dimana pencarian dilanjutkan jika terdapat langkah goal dan berhenti jika mencapai node tujuan.
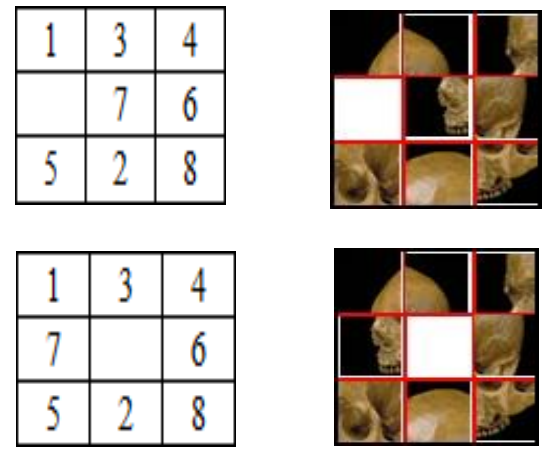

Gambar 5. Proses penyusunan gambar

Gambar diatas adalah lanjutan dari langkah selanjutnya dari metode best first search, dimana 
pencarian dilanjutkan jika terdapat langkah goal dan berhenti jika mencapai node tujuan.

\begin{tabular}{|l|l|l|}
\hline 1 & 3 & 4 \\
\hline 7 & 2 & 6 \\
\hline 5 & & 8 \\
\hline
\end{tabular}

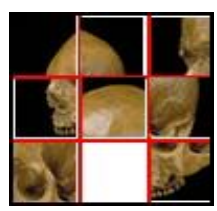

\begin{tabular}{|l|l|l|}
\hline 1 & 3 & 4 \\
\hline 7 & 2 & 6 \\
\hline 5 & 8 & \\
\hline
\end{tabular}

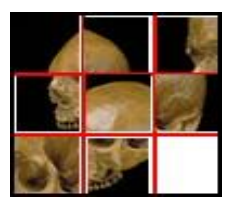

Gambar 6. Proses penyusunan gambar

Gambar diatas masih sama dengan langkah sebelumnya, yaitu metode best first search masih mencari langkah yang terdapat goal state.

\begin{tabular}{|l|l|l|}
\hline 1 & 3 & 4 \\
\hline 7 & 2 & \\
\hline 5 & 8 & 6 \\
\hline
\end{tabular}

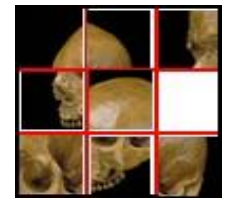

\begin{tabular}{|l|l|l|}
\hline 1 & 3 & \\
\hline 7 & 2 & 4 \\
\hline 5 & 8 & 6 \\
\hline
\end{tabular}

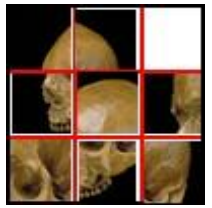

Gambar 7. Proses penyusunan gambar

Gambar diatas masih sama dengan langkah sebelumnya, yaitu metode best first search masih mencari langkah yang terdapat goal state.

\begin{tabular}{|l|l|l|}
\hline 1 & & 3 \\
\hline 7 & 2 & 4 \\
\hline 5 & 8 & 6 \\
\hline
\end{tabular}

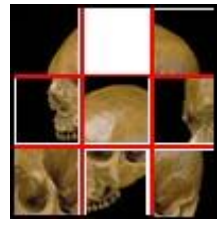

\begin{tabular}{|l|l|l|}
\hline 1 & 2 & 3 \\
\hline 7 & & 4 \\
\hline 5 & 8 & 6 \\
\hline
\end{tabular}

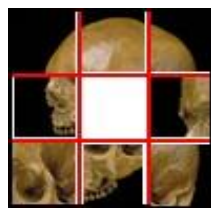

Program Studi Teknik Informatika Universitas Prima Indonesia (UNPRI) Medan
Gambar 8. Proses penyusunan gambar

Gambar diatas menampilkan jika metode best first search telah berhasil menyusun beberapa potongan gambar sesuai gambar aslinya, namun proses belum selesai dan akan dilanjutkan

\begin{tabular}{|l|l|l|}
\hline 1 & 2 & 3 \\
\hline 7 & 4 & \\
\hline 5 & 8 & 6 \\
\hline
\end{tabular}

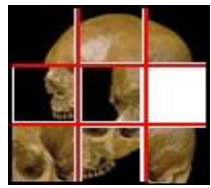

Gambar 9. Proses penyusunan gambar

Gambar diatas masih sama dengan langkah sebelumnya, yaitu metode best first search masih mencari langkah yang terdapat goal state.

\begin{tabular}{|l|l|l|}
\hline 1 & 2 & 3 \\
\hline 7 & 4 & 6 \\
\hline 5 & & 8 \\
\hline
\end{tabular}
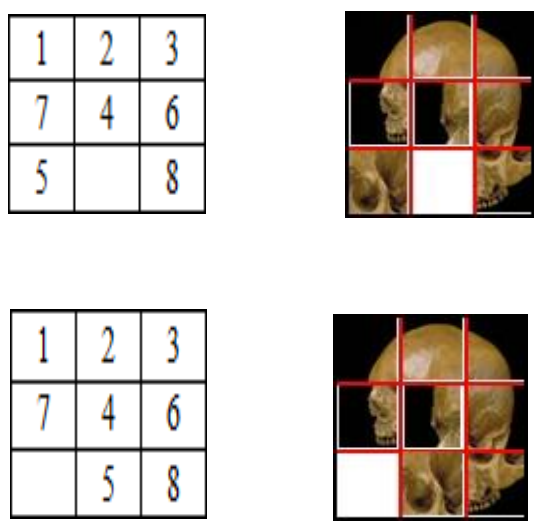

Gambar 10. Proses penyusunan gambar

Gambar diatas masih sama dengan langkah sebelumnya, yaitu metode best first search masih mencari langkah yang terdapat goal state.

\begin{tabular}{|l|l|l|}
\hline 1 & 2 & 3 \\
\hline 7 & 4 & 6 \\
\hline 5 & 8 & \\
\hline
\end{tabular}

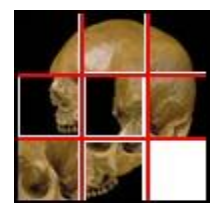

\begin{tabular}{|l|l|l|}
\hline 1 & 2 & 3 \\
\hline & 4 & 6 \\
\hline 7 & 5 & 8 \\
\hline
\end{tabular}

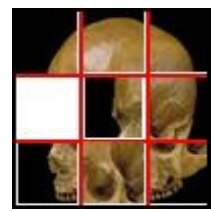




\begin{tabular}{|l|l|l|}
\hline 1 & 2 & 3 \\
\hline 4 & & 6 \\
\hline 7 & 5 & 8 \\
\hline
\end{tabular}

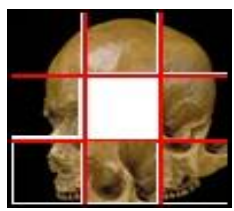

Gambar 11. Proses penyusunan gambar

Gambar diatas masih sama dengan langkah sebelumnya, yaitu metode best first search masih mencari langkah yang terdapat goal state.

\begin{tabular}{|l|l|l|}
\hline 1 & 2 & 3 \\
\hline 4 & 5 & 6 \\
\hline 7 & & 8 \\
\hline
\end{tabular}

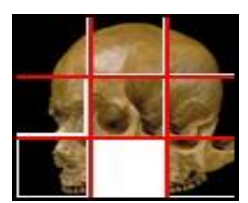

\begin{tabular}{|l|l|l|}
\hline 1 & 2 & 3 \\
\hline 4 & 5 & 6 \\
\hline 7 & 8 & \\
\hline
\end{tabular}

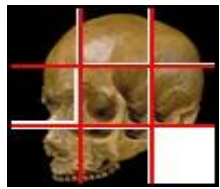

Gambar 12. Potongan gambar yang berhasil disusun

Gambar diatas adalah proses metode best first search telah selesai dan berhasil mencapai goal state yang dituju, dapat dilihat bahwa gambar berhasil tersusun dari yang sebelumnya diacak.

Secara konsep cara bermain Game Battle Puzzle ini yaitu pemain harus menyusun potongan gambar yang diacak berdasarkan gambar dan option yang telah dipilih sambil melawan komputer. Metode Best first search telah diuji dalam menyusun potongan gambar dan berhasil tersusun berdasarkan gambar asalnya.

Jika dilihat dari langkah-langkah metode diatas, metode best first search akan mengunjungi semua node yang ada dan melanjutkan langkahnya jika node tersebut terdapat goal dan akan berhenti jika mencapai node tujuan.

Langkah-langkah yang dilakukan metode best first search dalam menyelesaikan masalah adalah :

1. Buat sebuah stack kemudian inisialisasikan node akar sebagai node pertama.

2. Bila node pertama $\neq$ GOAL, node diganti dan dihapus dengan anak-anaknya.
3. Kemudian, keseluruhan node pada stack diurutkan secara ascending berdasarkan fungsi heuristic yang digunakan.

4. Bila node pertama $\neq$ GOAL, ulangi langkah 2. Bila node pertama $=\mathrm{GOAL}$, cari solusi dengan menelusuri jalur dari GOAL ke node akar.

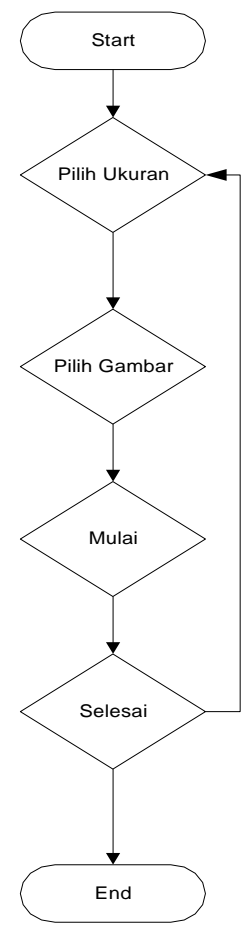

Gambar13. Flowchart Game

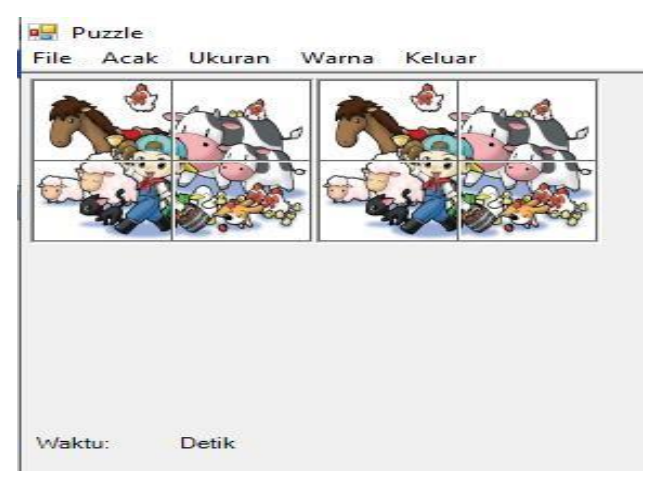

Gambar 14. Tampilan hasil pengujian

Dari hasil tampilan pengujian bahwa user harus bermain dengan cepat agar bisa menang melawan komputer, dimana user sendirilah yang akan memilih gambar yang akan disusun dan memilih potongan gambar yang tersedia $(2 \times 2,3 \times 3,4 \times 4)$. Algoritma 
Best First Search berperan sebagai pergerakan komputer dalam menyusun potongan gambar.

\section{Kesimpulan}

\subsection{Kesimpulan}

Adapun kesimpulan yang diperoleh adalah :

1. Algoritma Best first Search dapat diterapkanuntuk menyusun potongan gambar.

2. Algoritma Best first search dengan cepat dapat menysun potongan gambar yang diacak.

3. Game Battle Puzzle dapat dijadikan game yang menghibur dan dimainkan semua kalangan.

\subsection{Saran}

Adapun saran yang diperoleh adalah:

1. Game battle puzzle ini dapat dikembangakan agar memiliki potongan gambar yang lebih bervariasi.

2. Game ini dapat dikembangkan agar memiliki fiturfitur yang lebih baik.

\section{References}

[1] Marissa, Nanan Rohman, "Pencapaian goal state pada permainan 8 puzzle dengan menggunakan metode best first search", Jurnal Computech \& Bisnis, vol.2, ISSN 1978-9629, Desember 2008.

[2] Rian Apriandi, Tedy Rismawan, Dwi Marisa. "Penerapan metode best first search (BFS) untuk pencarian lokasi SPBU terdekat menggunakan arduino berbasis android". Jurnal coding, sistem komputer untan , vol.06 no.1, ISSN 2338-493x, 2018.

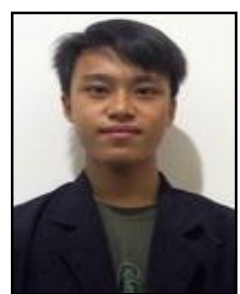

Aqil Muhammad Arviansyah, Lahir di medan 10 Oktober 1996 seorang mahasiswa Universitas Prima Indonesia Fakultas Teknologi dan IImu Komputer Program Studi S-1 Teknik Informatika. Memulai pendidikan di SD YPI Amir Hamzah lalu melanjutkan pendidikan di SMP Amir Hamzah dan SMA Amir Hamzah. Lulus sekolah pada tahun 2014 dan melanjutkan jenjang pendidikan di Universitas Prima Indonesia.

Anak kedua dari tiga bersaudara yang kini tinggal di Jl. Karya Medan ini bekerja di bidang administrasi pada kantor swasta di kota medan. 